University of Warwick institutional repository

This paper is made available online in accordance with

publisher policies. Please scroll down to view the document itself. Please refer to the repository record for this item and our policy information available from the repository home page for further information.

To see the final version of this paper please visit the publisher's website. Access to the published version may require a subscription.

Author(s): S Michie, K Jochelson, W A Markham, C Bridle

Article Title: Low-income groups and behaviour change interventions: a review of intervention content, effectiveness and theoretical frameworks Year of publication: 2009 Link to published version : http://dx.doi.org/10.1136/jech.2008.078725

Publisher statement: none 


\section{JECH}

\section{Low-income groups and behaviour change interventions: a review of intervention content, effectiveness and theoretical frameworks}

S Michie, K Jochelson, W A Markham and C Bridle

J Epidemiol Community Health 2009;63;610-622; originally published online 21 Apr 2009;

doi:10.1136/jech.2008.078725

Updated information and services can be found at:

http://jech.bmj.com/cgi/content/full/63/8/610

\section{These include:}

References This article cites 36 articles, 10 of which can be accessed free at: http://jech.bmj.com/cgi/content/full/63/8/610\#BIBL

Rapid responses You can respond to this article at:

http://jech.bmj.com/cgi/eletter-submit/63/8/610

Email alerting Receive free email alerts when new articles cite this article - sign up in the box at service the top right corner of the article

Topic collections Articles on similar topics can be found in the following collections

$$
\begin{aligned}
& \text { Health service research (5468 articles) } \\
& \text { Health education (13228 articles) } \\
& \text { Health promotion (14382 articles) } \\
& \text { Smoking ( } 6196 \text { articles) } \\
& \text { Smoking and tobacco (5600 articles) }
\end{aligned}
$$

\section{Notes}

To order reprints of this article go to: 


\title{
Low-income groups and behaviour change interventions: a review of intervention content, effectiveness and theoretical frameworks
}

\author{
S Michie, ${ }^{1}$ K Jochelson, ${ }^{2}$ W A Markham, ${ }^{3}$ C Bridle ${ }^{4}$
}

${ }^{1}$ Research Department of Clinical, Education and Health Psychology, University College London, London, UK; ${ }^{2}$ Equality and Human Rights Commission, London, UK; ${ }^{3}$ School of Health and Social Studies, University of Warwick, Coventry, UK; ${ }^{4}$ Clinical Trials Unit, Warwick Medical School, University of Warwick, Coventry, UK

Correspondence to: Professor S Michie, Research Department of Clinical, Education and Health

Psychology, University College London, 1-19 Torrington Place, London WC1E 7HB, UK;

s.michie@ucl.ac.uk

Accepted 2 March 2009

\begin{abstract}
Background: Interventions to change health-related behaviours have potential to increase health inequalities. Methods: This review investigated the effectiveness of interventions targeting low-income groups to reduce smoking or increase physical activity and/or healthy eating. Of 9766 papers identified by the search strategy, 13 met the inclusion criteria. Intervention content was coded into component technique and theoretical basis, and examined as a potential source of effect heterogeneity.
\end{abstract}

Results: Interventions were heterogeneous, comprising 4-19 techniques. Nine interventions had positive effects, seven resulted in no change and one had an adverse effect. Effective interventions had a tendency to have fewer techniques than ineffective interventions, with no evidence for any technique being generally effective or ineffective. Only six studies cited theory relative to intervention development, with little information about how theory was used and no obvious association with intervention content or effect.

Conclusion: This review shows that behaviour change interventions, particularly those with fewer techniques, can be effective in low-income groups, but highlights the lack of evidence to draw on in informing the design of interventions for disadvantaged groups.

Chronic diseases, such as cardiovascular disease, diabetes, cancer and respiratory disease, are a major cause of death and disability worldwide. There is considerable evidence showing that quitting smoking, eating a healthier diet, not consuming excessive amounts of alcohol and exercising regularly can have a major impact on reducing rates of chronic illness ${ }^{12}$ Lower socioeconomic status (SES) and lower social status is associated with poorer health outcomes and less healthy behaviours. ${ }^{3-6}$ For example, in Great Britain, although smoking prevalence has declined across all socioeconomic groups, $15 \%$ of managerial and professional groups smoked compared with $29 \%$ of manual occupational groups in 2006. While $30 \%$ of adults in managerial and professional groups eat the recommended five portions of fruit and vegetable a day, just $18 \%$ of adults in the routine and manual groups do so. ${ }^{8}$ Only $25 \%$ of people in lower socioeconomic groups participate in sports and exercise compared with about $50 \%$ of higher socioeconomic groups (although when occupational activity is controlled for, activity levels are similar). ${ }^{8}$ The adult routine and manual group is estimated at about 15 million people; about 4.3 million smoke, 12.3 million eat less than five fruit and vegetable portions a day, and 7.5 million are not physically active. ${ }^{10}$ Even a small percentage change in behaviour in lower socioeconomic groups could have a large impact on the health profile of the general population and on health costs.

The health promotion literature offers many theories and techniques on behaviour change, but thus far there has been little research analysing the effectiveness of particular component techniques, or of the effectiveness of techniques across different groups. Literature reviews of particular health behaviours point to the paucity of data on the impact of health promotion programmes on behaviour change in poor and socially excluded groups. ${ }^{11-13}$ Recent reviews also noted the lack of information at review or meta-review level on the variable effects of interventions on different socioeconomic groups and on the impact of interventions on reducing health inequalities ${ }^{14-16}$ Albarracin et al show that the impact of interventions is contingent on gender, age, ethnicity and other population-specific factors, suggesting that generic interventions cannot be applied across populations with confidence that they will be effective. ${ }^{16}$

There is clear evidence that people from disadvantaged backgrounds are less successful in achieving behaviour change following participation in formal programmes such as smokers' clinics. ${ }^{17} 18$ However, this does not necessarily mean that those programmes were less effective; it may be that those from disadvantaged backgrounds began with a lower chance of success because of their starting levels of behaviour, and their physical and/ or social environments undermine attempts at change. There is consistent evidence that smokers in low socioeconomic groups are significantly more likely to fail to quit smoking compared with smokers in higher socioeconomic groups. ${ }^{19}$ Community-based programmes promoting healthy eating and physical activity have more difficulty recruiting participants from low socioeconomic groups $^{20}$ and find higher attrition rates among low-income participants. ${ }^{21}$

Reducing health inequalities depends on developing interventions to increase healthy behaviours that are differentially effective in favour of those from disadvantaged backgrounds or that target socially disadvantaged groups. A recent review on behaviour change drew attention to the lack of reviews and primary studies investigating differential effectiveness among social groups and the lack of research on the cost-effectiveness of behaviour change interventions. ${ }^{15}$ The few studies that have investigated the effectiveness of interventions across socioeconomic groups have tended 
to do this as post hoc comparisons and are underpowered to do this, leading to equivocal results.

This review focuses on interventions specifically targeted at low-income populations, one index of disadvantage. It included three targeted behaviours related to health: smoking, healthy eating and physical activity. These were selected as they are highly associated with illness and death, eg, they constituted $70 \%$ of the modifiable behaviours found to be associated with death in the United States in 2000. ${ }^{22}$ This review analyses intervention content into its component techniques; such a detailed description is necessary for evaluating effectiveness and for understanding mechanisms of change. ${ }^{23}{ }^{24}$ Interventions are described using a reliable taxonomy of behaviour change techniques. ${ }^{25}$

The increasing recognition that interventions to change behaviour should draw on theories of behaviour and behaviour change in their development ${ }^{26}$ is for three main reasons. ${ }^{24}$ First, interventions are likely to be more effective if they target causal determinants of behaviour and behaviour change. Second, theory-based interventions facilitate an understanding of why particular interventions work and thus provide a basis for developing better interventions across different contexts, populations and behaviours. Third, theory can be advanced only if interventions and evaluations are theoretically informed. ${ }^{24}{ }^{25}$ However, many studies do not make the link between theoretical models, expected outcomes and the process of change explicit.

The aim of this review is to identify evidence for the effectiveness of health behaviour interventions that target lowincome groups, with the aim of reducing smoking and unhealthy eating or increasing physical activity. It focuses on the component techniques of the interventions, the theories used to develop the interventions, and considers associations between theory and intervention content, and between intervention content and effect. It should be stressed that this approach is unable to comment on differential effectiveness across social groups, only on whether there was any evidence of effect in interventions targeting low-income groups.

\section{METHOD}

\section{Search strategy}

We searched 21 electronic databases (January 1995 to September 2006) using search terms related to a low-income population (eg, socioeconomic status, deprivation, disadvantaged, income) and three behaviours related to health: smoking cessation, healthy eating and physical activity (see Appendix A for databases and Appendix B for example search strategies). In addition, we approached 24 experts in the health inequalities field enquiring about potential studies missed by our electronic search strategy, and we checked the bibliographies of all included studies.

\section{Screening}

Titles and abstracts were screened against the inclusion criteria by one reviewer, and a second reviewer independently checked a random $10 \%$ of the search results. Full-text papers of references that could not be excluded were ordered, and divided equally among two reviewers for assessment against the inclusion criteria. For each reviewer, all papers initially selected for inclusion, and a random $10 \%$ of papers initially excluded, were independently assessed by the other reviewer. Inter-rater agreement was very good, kappa $=0.81$.

\section{Eligibility criteria}

The eligibility criteria for inclusion in this study were:

1. Population: non-clinical, general population adults (18+ years) from a low-income group.

2. Interventions: any interventions promoting smoking cessation, healthy eating and/or physical activity targeted at low-income groups.

3. Outcomes: behavioural outcomes relevant to the intervention target, ie, smoking cessation and increased healthy eating and physical activity.

4. Date: published after January 1995.

5. Language: published in the English language.

6. Methodological criteria: concurrent control, with or without random allocation. This therefore excludes reviews.

\section{Data extraction}

A reviewer extracted data from the primary studies and a second reviewer checked all papers for accuracy; discrepancies were resolved through discussion. The interventions were coded by study design, country, target behaviour, type of participant, type of theory cited by the authors as informing the intervention, type of intervention and intervention effect. Intervention content was analysed into component techniques, using a reliable published taxonomy of 26 techniques, ${ }^{35}$ but two additional techniques were also identified. When interventions targeted more than one behaviour, the techniques and results were recorded for each behaviour.

\section{Data analysis}

Owing to the heterogeneity in intervention content and design, and the small sample, meta-analysis was not appropriate. The number of techniques in effective and ineffective interventions were tested statistically using independent t-tests.

\section{RESULTS}

\section{Available evidence}

As figure 1 illustrates, the search strategy identified 9766 references to potentially relevant studies, of which 1468 were duplicates. We screened 8298 distinct references, excluding 8025 primarily because the study populations were not of low income. We ordered full-text copies of the remaining 273 references, and assessed 264 (nine could not be obtained, see Appendix C), of which 238 were excluded primarily for failing to satisfy the population criterion. A total of 13 studies,

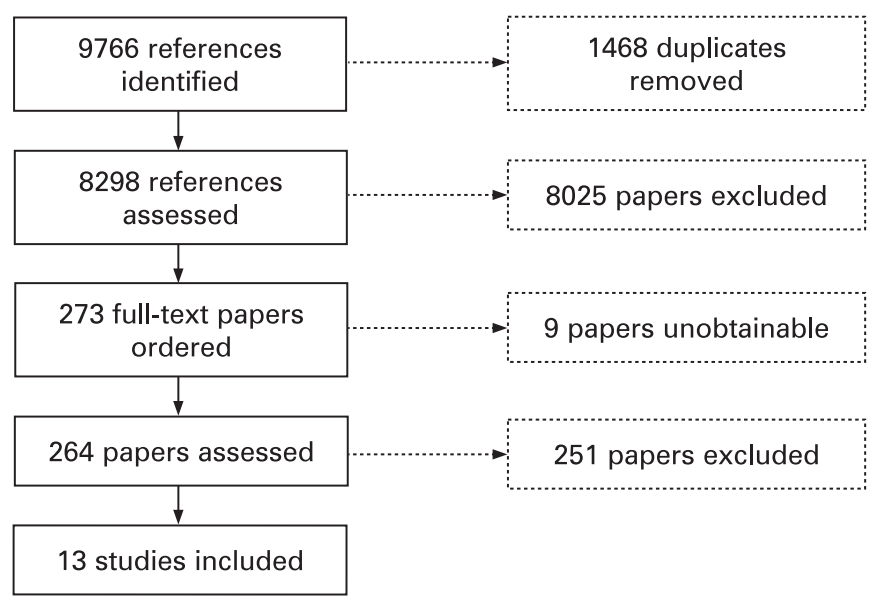

Figure 1 Flow of study papers through the review. 
reporting 17 comparisons of interest, were included in the review (see table 1 ).

Of the 13 studies included in the review, three were conducted in the United Kingdom, ${ }^{31} 3839$ one in Canada, ${ }^{34}$ eight in the USA, ${ }^{27-30} 3233{ }^{40-43}$ and one in the Netherlands. ${ }^{44}$ In total, seven, six and four studies developed interventions to promote smoking cessation, healthy eating and physical activity, respectively, with three studies targeting more than one behaviour..$^{32-34}$

Eight studies were randomised controlled trials (RCTs), ${ }^{28} 30-3238394243$ and five studies evaluated interventions among a non-randomised cohort with concurrent control. ${ }^{33} 34404144$ Sample sizes ranged from 15 to more than 2000, although most were between 200 and 1000, with an average approaching 500. Effect data were extracted for the final followup, which ranged from less than 6 months ${ }^{28}$ to between 6 and 12 months, ${ }^{30} 3233394243$ to 12 months or more. ${ }^{31} 3438404144$ None of the studies investigated cost-effectiveness.

\section{Intervention techniques}

Interventions were very heterogeneous, incorporating anything from 4 to 19 techniques. Figure 2 shows the number of interventions incorporating each technique (multiple behaviours targeted by one study intervention are counted as separate interventions). Those used most frequently (in at least 9 of the 17 interventions) were: providing general information; providing information about the consequences of a particular behaviour; helping to form an intention to change a behaviour; setting specific goals; identifying barriers to changing behaviour; planning social support or social change; and providing rewards contingent on performing the behaviour.

\section{Intervention content and effects}

Overall, nine interventions had positive effects, seven resulted in no detectable change and one had an adverse effect. For smoking, four studies reported a positive effect, ${ }^{28}{ }^{39-41}$ and three reported no effects. ${ }^{34} 4243$ For healthy eating, four studies reported positive effects ${ }^{30} 323844$ and two reported no effects. ${ }^{33} 34$ For physical activity, one study reported a positive effect, ${ }^{31}$ two no effects ${ }^{32}{ }^{33}$ and one an adverse effect. ${ }^{34}$ Overall, five of the nine positive intervention effects were obtained from RCTs aimed at promoting healthy eating, ${ }^{30} 3238$ physical activity ${ }^{31}$ and smoking cessation, ${ }^{39}$ three of which were conducted in the UK. ${ }^{31} 38$ Differing sample sizes do not appear to explain differences in effectiveness, as there was no difference between sample sizes for effective interventions $(M=665, \mathrm{SD}=812)$ and those having no effect $(M=613, S D=443 ; \quad t(11)=0.12$, $\mathrm{p}=0.91)$.

Effective interventions had a tendency to have fewer techniques on average than ineffective interventions; an independent t-test demonstrated that this reached marginal statistical significance (8.22 vs $12.75 ; \mathrm{t}(15)=-1.95, \mathrm{p}=0.07$; $95 \%$ CI for mean difference -9.48 to 0.43 ) (fig 3 ). Figure 4 compares the frequency with which techniques are included in effective and ineffective interventions. The most commonly used techniques were providing information (the first three techniques in figure 4) and facilitating goal setting (the second two techniques in fig 4). Visual inspection suggests that all the techniques have potential merit, with none appearing to be overwhelmingly effective or ineffective.

\section{Effects over time}

The effects of behaviour change interventions may ameliorate over time, such that significant intervention effects are less likely to be observed in studies with longer follow-ups. In this review, however, there is no evidence of a time-dilution effect, but evidence suggests the reverse. Of the nine positive effects reported among the included studies, four were obtained in studies with follow-up $<12$ months, and five in studies with $\geqslant 12$ month follow-ups. Indeed, with only one exception, ${ }^{34}$ studies with long-term follow-up reported only positive intervention effects, with non-significant effects therefore clustered among studies with shorter term follow-up. Of course, results based on indirect comparison must be interpreted with caution. Nevertheless, it is plausible to speculate that the effects of interventions targeting low-income groups may take longer to emerge, and/or have effects that may be more durable or sustainable over time. Resolving these issues may have

Figure 2 Technique type and frequency.

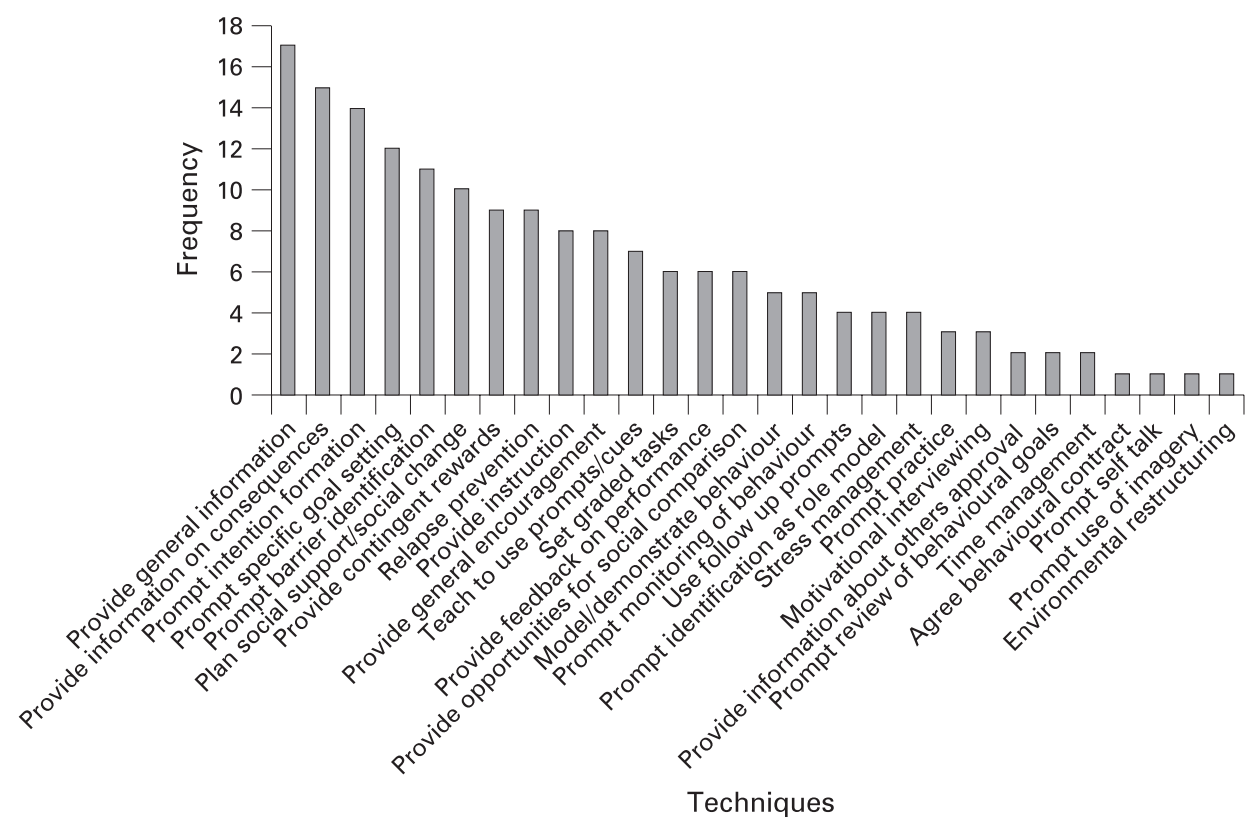




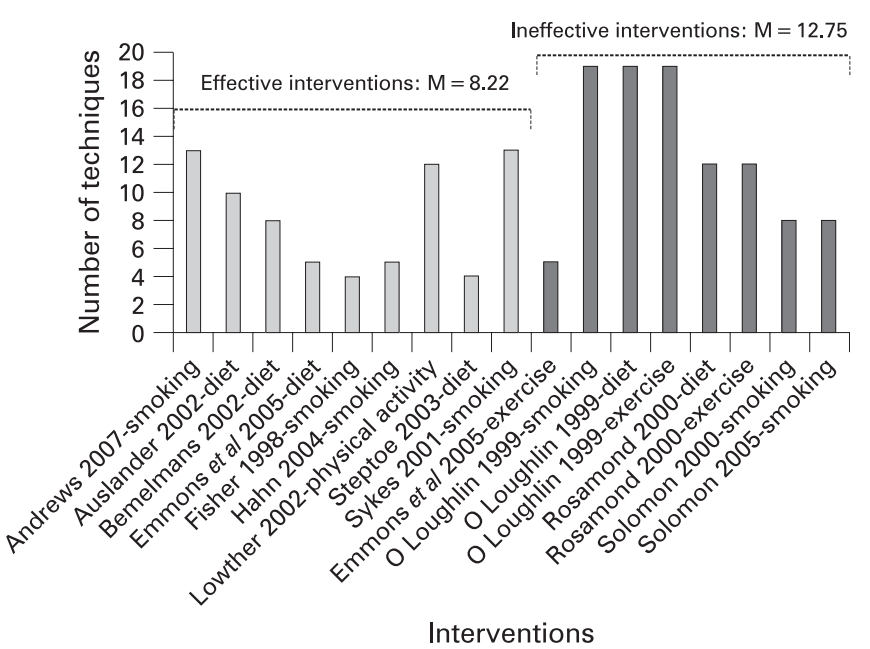

Figure 3 Number of techniques used in effective and ineffective interventions.

profound effects on intervention development, research design and, ultimately, reducing health inequalities among low-income groups.

\section{Theoretical base of interventions}

Theories were cited in 6 of the 13 included studies, incorporating 10 of the 17 comparisons, four studies drawing on more than one theory. Five studies cited the stages of change/ transtheoretical model, four studies cited social cognitive theory, and five theories were cited only once: the theory of reasoned action, the precaution adoption model, the precedeproceed model, behaviour modification principles and organisational theory. There was thus a plethora of theories used in these few studies. None of the papers reported how the stated theories were used as a basis for selecting the techniques comprising the intervention, and none drew conclusions about theory from the evaluation data. There were no obvious differences in intervention content (ie, the techniques used within the intervention) between those studies that explicitly used theory and those that did not. There was also no obvious association between reported use of theory and whether or not the intervention was effective.

\section{DISCUSSION}

There is evidence that behaviour change interventions can be effective in low-income groups. Of the 17 intervention evaluations that targeted low-income groups, we found that nine were effective, seven were not statistically different and one suggested adverse effects. That nine statistically significant positive results were obtained purely by chance seems unlikely. However, the small number of studies means that the results should be treated with caution.

The most frequently used intervention techniques were providing information (eg, about the consequences of the behaviour) and prompting people to form intentions and set goals. No clear patterns between the purported theoretical basis, intervention content and the effect were evident, although the dataset was too small for formal analysis. In addition, the lack of reported detail as to how theory was used in designing interventions precludes the possibility of explaining a lack of association. It may be that particular theories were not useful for intervention development, or that useful theories were poorly applied.

There are two suggestive findings from this review. The first is that more focused interventions involving a small set of techniques may be more effective than interventions combining a large number of different techniques. There may be more variation in the quality of intervention delivery as the number of component techniques increases, both within and between providers, increasing the likelihood of inconsistent effects. This highlights the need to monitor the fidelity of intervention delivery, ${ }^{45}{ }^{46}$ an important practice that is rarely observed. More research based on larger datasets is required to clarify these issues.

The second suggestive finding is that the most common techniques - providing information, facilitating goal setting and prompting barrier identification-may be helpful for lowincome groups. These sets of techniques may be working additively, in that providing information about the benefits of changing behaviour may increase people's motivation to change, while helping people to form specific, realistic goals, identify barriers and draw on social support may help people to translate motivation into action. This has some parallels with a finding from Coulter and Ellins' systematic review of patientfocused interventions. ${ }^{47}$ They found that providing information, on its own, had little effect on people's knowledge about their own health. However, combined with professional consultation
Figure 4 Number of effective and ineffective interventions using each technique.

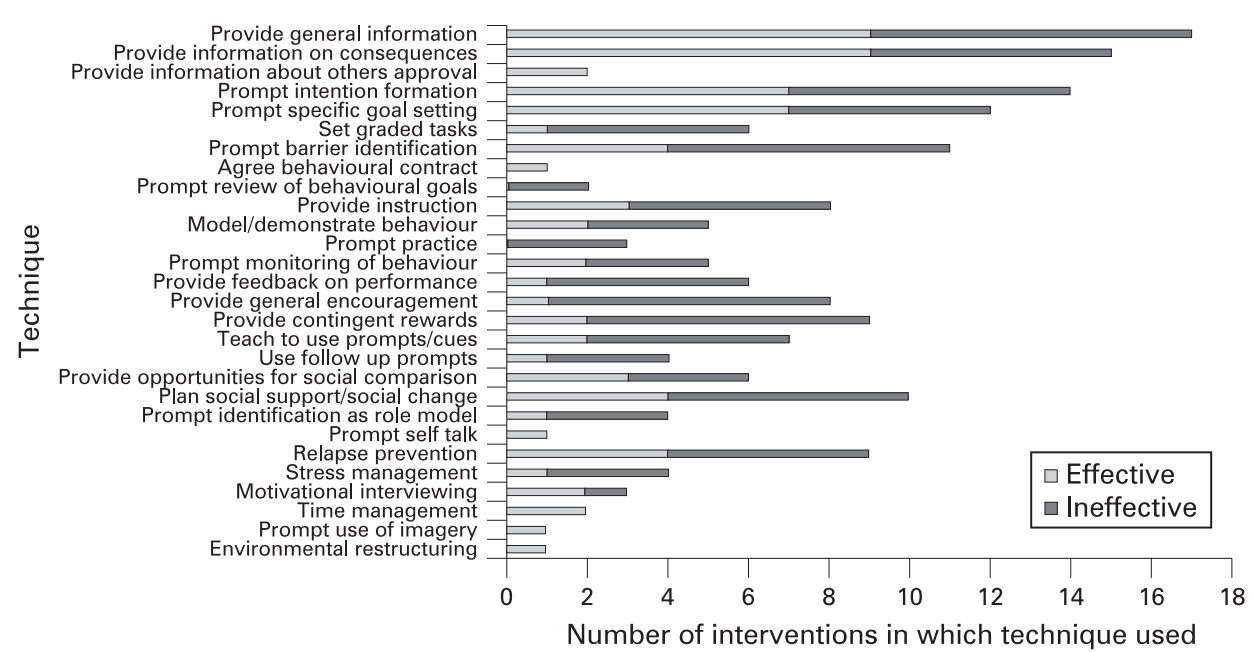



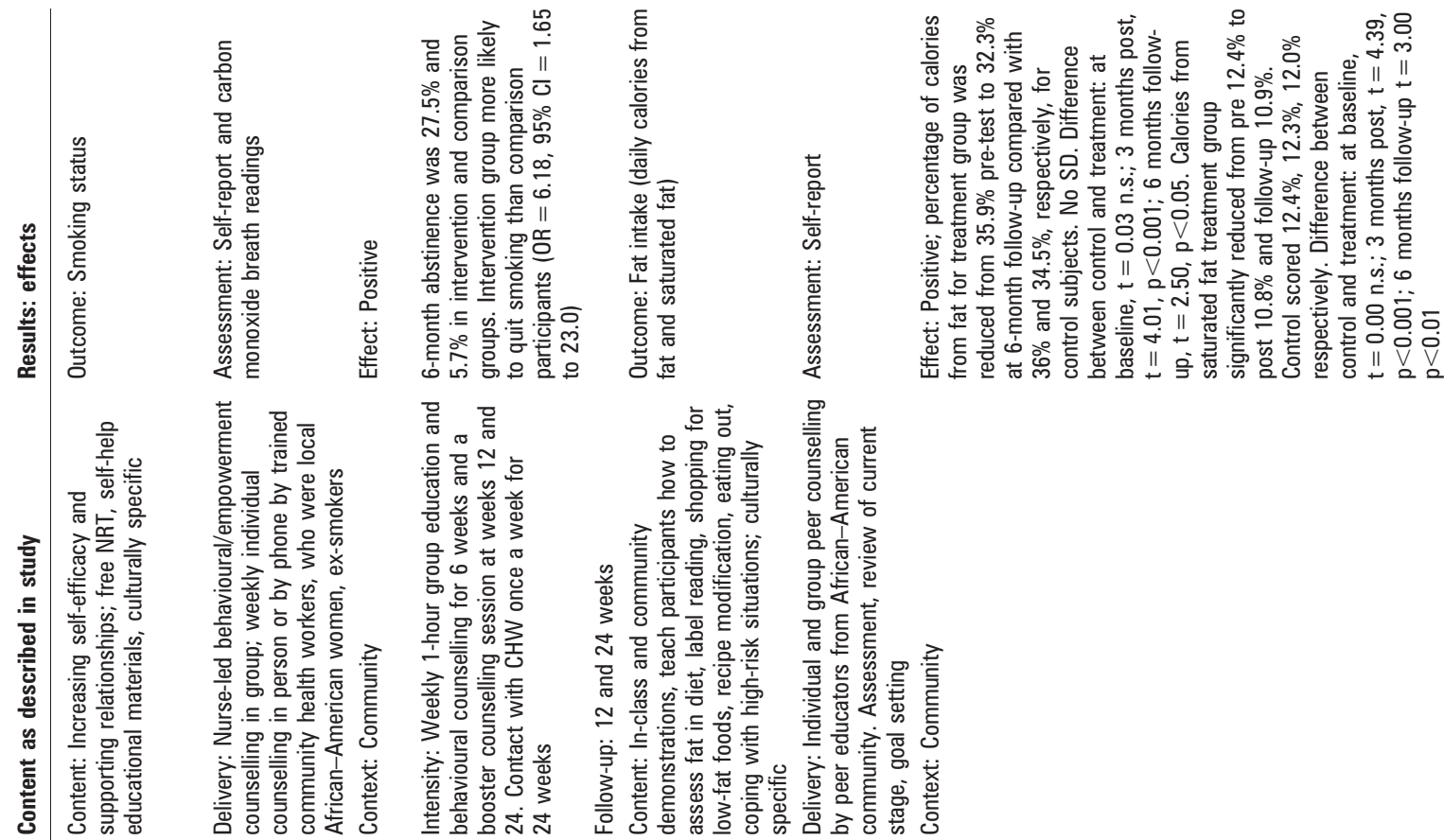

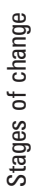

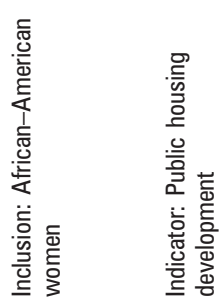<smiles>CC(C)[C@H]1C[C@@H]2C[C@H]1[C@@H]2C</smiles>

흠

$\stackrel{+}{Z}$
$\ddot{z}$ 


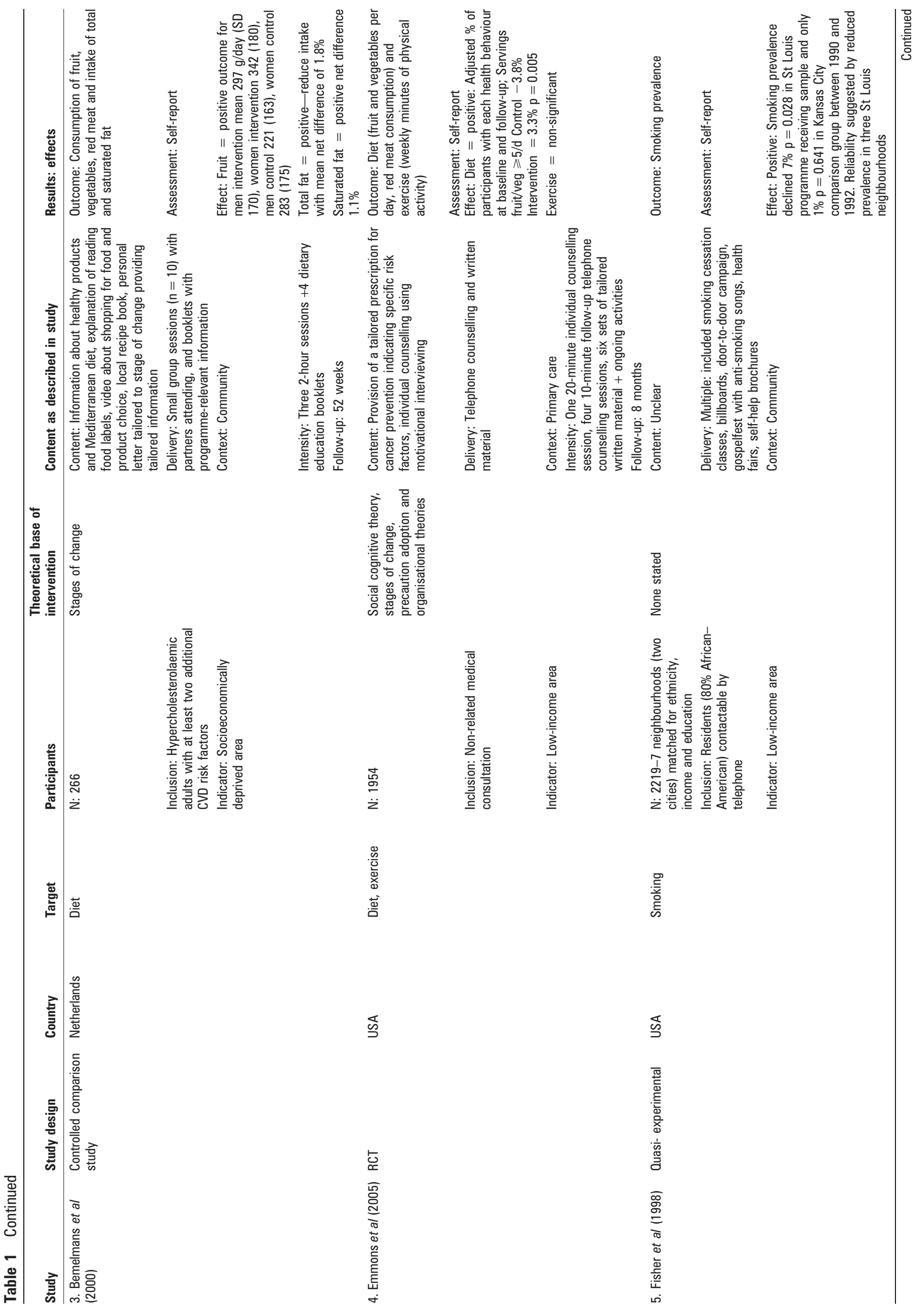




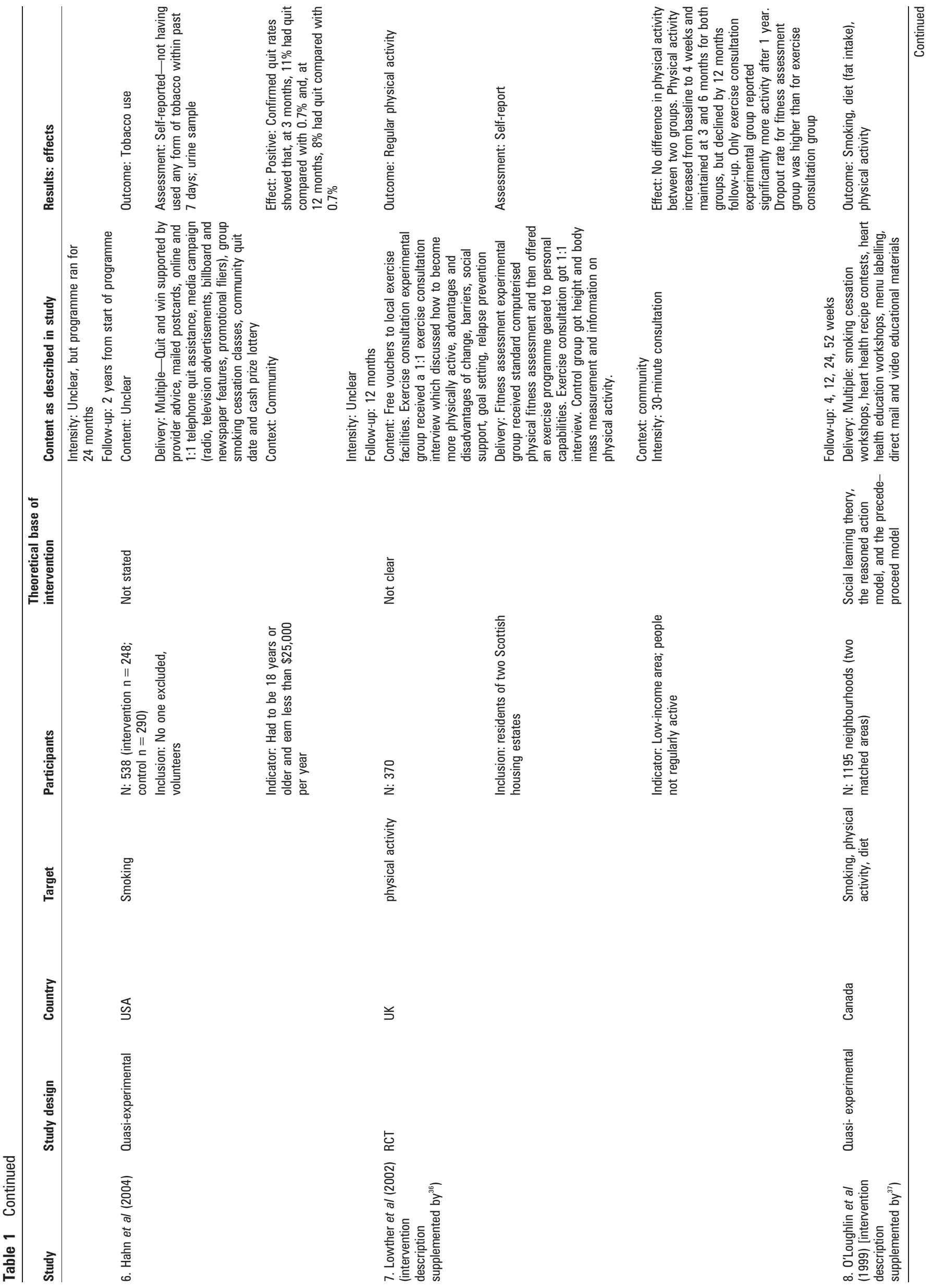




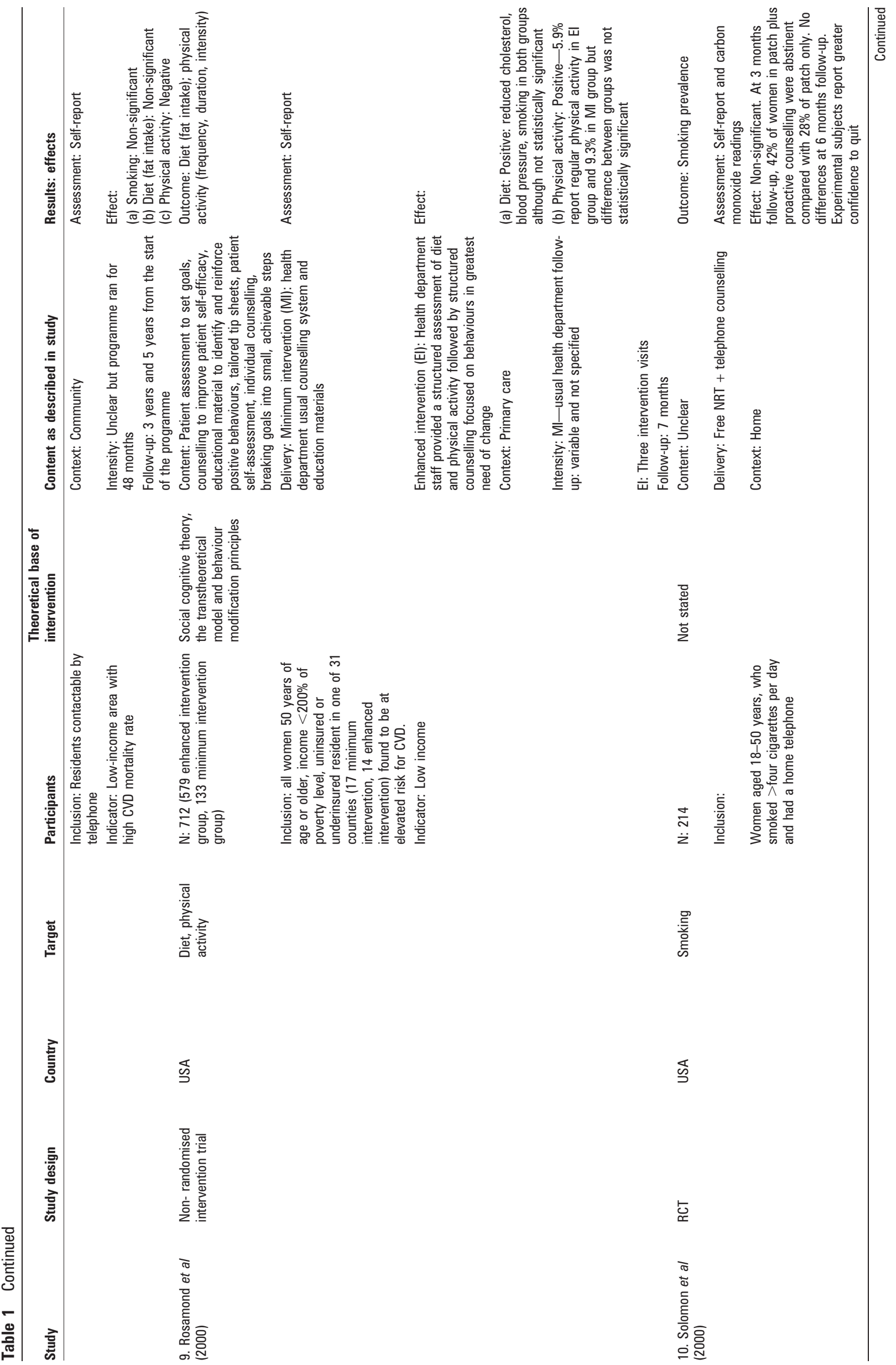




\section{Essay}

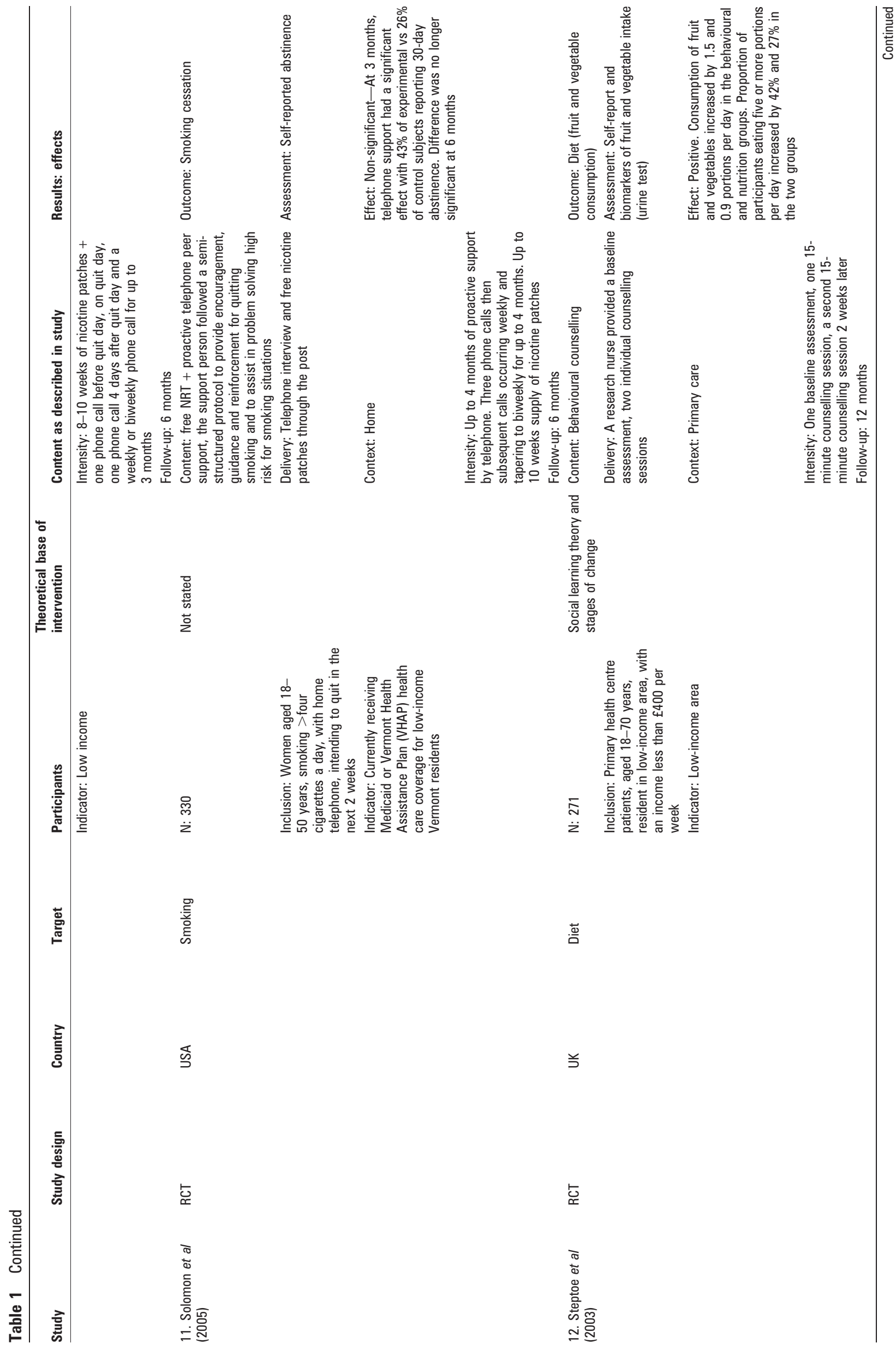




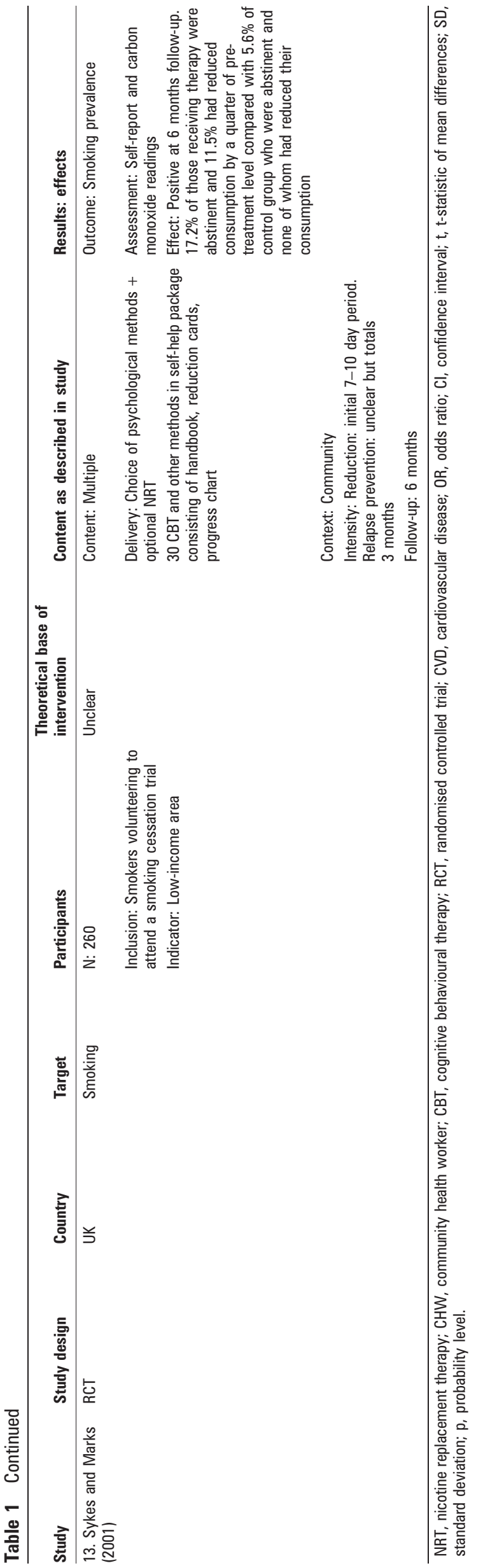

or advice, it could improve knowledge and recall, especially where the information was personalised. Disadvantaged populations benefited more than other groups, possibly because their knowledge base was smaller, and so they had more to gain from health information. It is also consistent with a meta-analysis of interventions to increase HIV preventive behaviours. ${ }^{16}$ Providing information changed behaviour only when accompanied by active, behavioural strategies such as teaching self-management techniques.

Goal setting is a key behaviour change technique in evidencebased theories of behaviour change, most notably social cognitive theory ${ }^{48}$ and self-regulation (control) theory. ${ }^{49}$ Setting goals that are realistic and achievable helps people to feel more confident about being able to change their behaviour. Setting goals may also help people to be more aware of their current behaviour and to take steps when they notice their behaviour is falling short of their targets. Breaking down large, long-term goals into smaller, short-term goals allows people to build on small successes, leading to greater feelings of control or "mastery". This may be especially important for those in disadvantaged situations, who often experience a lack of control and therefore feel powerless to bring about change. Emerging research findings suggest that adults with a low income or a high school education or less score poorly on the "patient activation measure". This measures an individual's confidence, knowledge and skills to take action to improve their health and stay the course even under stress. ${ }^{50}$ Goal setting is a relatively simple technique that can be successfully taught to a wide range of people varying in educational and social background, but disadvantaged groups may have more to gain, if their confidence and skill base is lower. ${ }^{51-54}$

Our scoping review is, by definition, not exhaustive. Given that only three of the 13 interventions were conducted in the UK and nine were from North America, caution needs to be exercised about the generalisability of the findings. In addition, the scope of the review did not extend to consider studies that directly compared the effectiveness of an intervention in lowincome groups versus more affluent groups. It is therefore not clear whether interventions to change these behaviours are differentially effective across socioeconomic groups. Two reviews have used a similar taxonomy of techniques for investigating intervention techniques in populations not selected by socioeconomic status and were able to use metaregression in much larger datasets. ${ }^{12}{ }^{55}$ They identified selfmonitoring of behaviour as the most effective technique. However, within-study comparisons are needed to answer the question as to whether different techniques, or different modes of delivery, tailored so as to be more relevant or attractive, are needed to promote health among lower income groups.

However, this review shows that there is a widespread paucity of evidence about the effectiveness and cost-effectiveness of changing health behaviours in disadvantaged groups. To build evidence about "what works for whom", it is essential that the same intervention be compared across different groups, and that different interventions be compared in the same groups. As this review demonstrates, such work is in its infancy.

For those with responsibility for commissioning or conducting systematic reviews in this or related areas, there is a need to consider carefully methods for maximising the inclusion of relevant evidence. First, reviews may need to include other study designs that adequately balance methodological reliability and contextual relevance. Second, future reviews may need to consider evidence obtained from a wider range of individuals. For example, our review focused on evidence that reported 


\section{What this study adds}

- There are few well-conducted evaluations of interventions to change health behaviours targeted at low-income groups.

- An innovative method of specifying intervention content using a reliable taxonomy of techniques.

- The most frequently used techniques included goal setting, planning social support/change and providing rewards.

- Such interventions can be effective for low-income groups.

- There was no difference in intervention content or outcome between studies that said they used theory and those that did not.

outcomes in adults, excluding evidence that targeted low SES adults but reported outcomes only in their children. Third, future reviews should consider the implications of using different indicators of social disadvantage. For example, in our review, the population of interest was defined as low income, but that meant the review excluded "culturally sensitive/ targeted" interventions that were not explicitly indexed under terms related to SES.

A dedicated stream of research funding for research into interventions targeting health behaviour change among low SES groups would thus seem to be timely and warranted. For such investment to maximise its potential to improve population health, the study of interventions to change behaviour should be informed by methods for analysing interventions by their component techniques and underlying theories of behaviour change. This will facilitate building evidence about, not just "what works" but how interventions work, evidence that is crucial for the future development of more effective interventions.

Funding: This review was funded by the King's Fund.

Competing interests: None.

\section{REFERENCES}

1. World Cancer Research Fund, American Institute of Cancer Research. Food, nutrition, physical activity and the prevention of cancer: a global perspective. Washington DC: Institute of Cancer Research, 2007.

2. World Health Organization. The world health report 2002. Reducing risks to health, promoting healthy life. Geneva: World Health Organization, 2002.

3. Kawachi I, Kennedy BP, Wilkinson RG, eds. The society and population health reader. Vol. 1. Income inequality and health. New York: New Press, 1999

4. Marmot M. Status syndrome: how your social standing directly affects your health and life expectancy. London: Bloomsbury, 2004.

5. Wilkinson RG. Unhealthy societies: the afflictions of inequality. London: Routledge, 1996.

6. Wilkinson RG, Marmot M, eds. Social determinants of health. Oxford: Oxford University Press, 1999.

7. Office of National Statistics. Prevalence of cigarette smoking by sex and socioeconomic classification based on the current or last job of the household reference person. http://www.statistics.gov.uk/hub/health-social-care/index.html. 2005 (accessed 26 May 2009).

8. NHS Health and Social Care Information Centre. Health survey for England: health of ethnic minorities. http://www.ic.nhs.uk/statistics-and-data-collections/ health-and-lifestyles-related-surveys/health-survey-for-england/health-survey-forengland-2004-health-of-ethnic-minorities-headline-tables. 2004.

9. Office of National Statistics. Census 2001. http://www.statistics.gov.uk/census/ default.asp. 2001 (accessed 26 Feb 2008).

10. Office of National Statistics. Labour Force Survey, Table 3.6 D7665. http://www. statistics.gov.uk/STATBASE/Product.asp?vInk=14248. 2003 (accessed 26 Feb 2008).

11. Hillsdon M, Foster C, Caill N, et al. The effectiveness of public health interventions for increasing physical activity among adults: a review of reviews, 2nd edn. London: Health Development Agency, 2005.

12. Michie S, Abraham C, Whittington $\mathrm{C}$, et al. Effective techniques in healthy eating and physical activity interventions: a meta-regression. Health Psychol in press

13. Naidoo B, Warm D, Quigley R, et al. Smoking and public health: a review of reviews of interventions to increase smoking cessation, reduce smoking initiation and prevent further uptake of smoking. London: Health Development Agency, 2004.
14. Blaxter M. Evidence for the effect on inequalities in health of interventions designed to change behaviour. http://www.nice.org.uk/nicemedia/pdf/

Evidencefortheeffectonlnequalitiesdesignedtochangebehavior.pdf. 2007 laccessed 19 Feb 2008).

15. National Institute for Health and Clinical Excellence. Behaviour change at population, community and individual levels. Public health programme guidance 6 . London: National Institute of Health and Clinical Excellence, 2007.

16. Albarracin D, Gillette JC, Earl AN, et al. A test of major assumptions about behaviour change: a comprehensive look at the effects of passive and active HIVprevention interventions since the beginning of the epidemic. Psychol Bull 2005;131:856-97.

17. Kidd KE, Altman DG. Adherence in social context. Controlled Clin Trials 2000;21:694-6.

18. Ferguson J, Bauld L, Chesterman J, et al. The English smoking treatment services: one-year outcomes. Addiction 2005;100:59-69.

19. Bell K, McCullough L, Greaves L. The effectiveness of National Health Service intensive treatments for smoking cessation in England: a systematic review. London: National Institute for Clinical and Health Excellence, 2006.

20. Bernal G, Sharron-del-Rio MR. Are empirically supported treatments valid for ethnic minorities? Toward an alternative approach for treatment research. Cult Diversity Ethnic Minority Psychol 2001;7:328-42.

21. Yancey AK, Ortega AN, Kumanyika SK. Effective recruitment and retention of minority research participants. Annu Rev Public Health 2006;27:1-28.

22. Mokdad AH, Marks JS, Stroup DF, et al. Actual causes of death in the United States, 2000 (vol. 291, pp. 1238, 2004). J Am Med Assoc 2004;293:293-4.

23. Michie S. Designing and implementing "behaviour change" interventions to improve population health. J Health Serv Res Policy 2008;13:64-9.

24. Michie S, Johnston M, Francis J, et al. From theory to intervention: mapping theoretically derived behavioural determinants to behaviour change techniques. App/ Psychol Int Rev 2008;57:660-80.

25. Michie S, Abraham C. Identifying techniques that promote health behaviour change: evidence based or evidence inspired? Psychol Health 2004;19:29-49.

26. Campbell M, Fitzpatrick R, Haines A, et al. Framework for design and evaluation of complex interventions to improve health. BMJ 2000;321:694-6.

27. Andrews J0, Bentley DNP, Crawford CHW, et al. Using community-based participatory research to develop a culturally sensitive smoking cessation intervention with public housing neighbours. Ethnicity Disease 2007;17:331-7.

28. Andrews J0, Felton G, Wewers ME, et al. Sister to sister: a pilot study to assist African American women in subsidized housing to quit smoking. Southern Online J Nursing Res 2005;6:23-31.

29. Auslander W, Haire-Joshu D, Houston C, et al. The short term impact of a health promotion program for low-income African American women. Res Social Work Pract 2000;10:78-97.

30. Auslander W, Haire-Joshu D, Houston C, et al. A controlled evaluation of staging dietary patterns to reduce the risk of diabetes in African-American women. Diabetes Care 2002;25:809-14.

31. Lowther M, Mutrie N, Scott EM. Promoting physical activity in a socially and economically deprived community: a 12-month randomized control trial of fitness assessment and exercise consultation. J Sport Sci 2002;20:577-88.

32. Emmons KM, Stoddard AM, Fletcher R, et al. Cancer prevention among working class, multiethnic adults: results of the healthy directions-health centers study. Am J Public Health 2005;95:1200-5.

33. Rosamond WD, Ammerman AS, Holliday JL, et al. Cardiovascular disease risk factor intervention in low-income women: the North Carolina WISEWOMAN project. Prev Med 2000;31:370-9.

34. O'Loughlin J, Paradis G, Gray-Donald K, et al. The impact of a community-based heart disease prevention program in a low-income, inner-city neighborhood. Am J Public Health 1999;89:1819-26.

35. Abraham C, Michie S. A taxonomy of behavior change techniques used in interventions. Health Psychol 2008;27:379-87.

36. Loughlan C, Mutrie N. Conducting an exercise consultation: guidelines for health professionals. J Inst Health Educ 1995;33:78-82.

37. Paradis G, O'Loughlin J, Elliott M, et al. A heart health promotion programme in a low income, low education neighbourhood in Montreal, Canada: theoretical model and early field experience. J Epidemiol Community Health 1995;49:503-12.

38. Steptoe AL, Perkins-Porras EA, McKay C, et al. Behavioural counselling to increase consumption of fruit and vegetables in low income adults: randomised trial. BMJ 2003;326:855-8.

39. Sykes CM, Marks DF. Effectiveness of a cognitive behaviour therapy self-help programme for smokers in London, UK. Health Promotion Int 2001;16:255-60.

40. Fisher EB, Auslander WF, Munro JF, et al. Neighbors for a smoke free north side: evaluation of a community organization approach to promoting smoking cessation among African Americans. Am J Public Health 1998;88:1658-63.

41. Hahn EJ, Rayens MK, Chirila C, et al. Effectiveness of a quit and win contest with a low-income population. Prev Med 2004;39:543-50.

42. Solomon LJ, Scharoun GM, Flynn BS, et al. Free nicotine patches plus proactive telephone peer support to help low-income women stop smoking. Prev Med 2000;31:68-74.

43. Solomon LJ, Marcy TW, Howe KD, et al. Does extended proactive telephone support increase smoking cessation among low-income women using nicotine patches? Prev Med 2005;40:306-13. 
44. Bemelmans WJ, Broer J, Vries JH, et al. Impact of Mediterranean diet education versus posted leaflet on dietary habits and serum cholesterol in high risk population for cardiovascular disease. Public Health Nutr 2000;3:273-83.

45. Bellg AJ, Borrelli B, Resnick B, et al. Enhancing treatment fidelity in health behavior change studies: best practice and recommendations from the Behavior Change Consortium. Health Psychol 2004;23:443-51.

46. Hardeman W, Michie S, Fanshawe T, et al. Fidelity of delivery of a physical activity intervention: predictors and consequences. Psychol Health 2008;23:11-24.

47. Coulter A, Ellins J. Effectiveness of strategies for informing, educating and involving patients. BMJ 2007;335:24-7.

48. Bandura A. Social foundations of thought and action: a social cognitive theory. Englewood Cliffs, NJ, USA: Prentice Hall, 1986.

49. Carver CS, Scheier MF. Themes and issues in the self-regulation of behavior. In: Wyer RS, ed. Perspectives on behavioral self-regulation. London: Lawrence Erlbaum Associates, 1999:1-105.

50. Hibbard JH, Stockard J, Mahoney ER, et al. Development of the Patient Activation Measure (PAM): conceptualising and measuring activation in patients and consumers. Health Service Res 2004;39:1005-26.

51. Heneman K, Block-Joy A, Zidenberg-Cherr S, et al. A "contract for change" increases produce consumption in low income women: a pilot study. J Am Dietetic Assoc 2005;105:1793-6.

52. Mayer JA, Jermanovich A, Wight BL, et al. Changes in the health behaviours of older adults: the San Diego Medicare Preventive Health Project. Prev Med 1994;23:127-33.

53. Kelley K, Abraham C. RCT of a theory-based intervention promoting healthy eating and physical activity amongst out-patients older than 65 years. Soc Sci Med 2004;59:787-97.

54. Glasgow RE, Toobert DJ, Hampson SE, et al. Implementation, generalization and long-term results of the "choosing well" of diabetes self-management intervention. Patient Educ Counselling 2002;48:115-22.

55. Dombrowski S, Sniehotta FF, Avenel A, et al. Identifying active ingredients in complex behavioural interventions for obese adults with additional risk factors: a systematic review. Under review.

\section{APPENDICES}

\section{A. Databases searched}

The following databases were searched from January 1995 to September 2006:

- ASSIA (Applied Social Sciences Index and Abstracts)

- BiblioMap

- CCTR (Cochrane Controlled Trials Register)

- CDP (Chronic Disease Prevention)

- CDSR (Cochrane Database of Systematic Reviews)

- CHID (Combined Health Information Database)

- CINAHL (Cumulative Index for Nursing and Allied Health Literature)

- DARE (Database of Abstracts of Reviews of Effectiveness)

- Dissertation Abstracts

- Econlit (Economic Literature)

- EMBASE

- GreyLit (British Library grey literature collection)

- HealthStar

- HMIC (Healthcare Management Information Consortium)

- MEDLINE

- NHS EED (NHS Economic Evaluation Database)

- Popline (Population Health and Family Planning)

- Psychinfo

- Social Science Citation Index

- Social Policy and Practice

- Sociofile

\section{B. Example search strategies \\ ASSIA 220906}

Query(CSA) ((KW = (socioeconomic or socio-economic) and $\mathrm{KW}=\left(\right.$ status or factor $\left.\left.{ }^{\star}\right)\right)$ $\mathrm{OR}\left(\mathrm{KW}=\left(\left(\right.\right.\right.$ low income) or poverty or disadvantage*) or $\mathrm{KW}=$ deprive $\left.\left.^{*}\right)\right)$ AND (KW $=$ (lifestyle* or activit* or inactivit*) or $\mathrm{KW}=$ (lweight gain) or overweight or obes $\left.^{*}\right)$ or KW $=\left(\left(\right.\right.$ food habit*) or (poor diet $\left.\left.\left.{ }^{*}\right)\right)\right)$ AND ((KW $=$ ((healthy eating) or fruit* or vegetable* ${ }^{*}$ or $\mathrm{KW}=\left(\right.$ exercis $^{*}$ or (health behaviour $\left.{ }^{*}\right)$ or $\left(\right.$ Health behavior $\left.\left.{ }^{*}\right)\right)$ OR $(\mathrm{KW}=($ interven* or Intervention*)))

\section{Cinahl (Ovid) 220906}

1. socioeconomic factor $\$ . t i, a b$.

2. exp Socioeconomic Status/

3. socioeconomic status.ti,ab.

4. (disadvantage $\$$ or depriv\$ or poverty or low income).ti,ab.

5. (SES and status and low).ti,ab.

6. or/1-5

7. $\exp$ LIFESTYLE/
8. lifestyle\$.ti,ab.

9. (activit\$ or inactivit\$).ti,ab.

10. ((weight and gain) or overweight).ti,ab.

11. exp OBESITY/

12. obesity.ti,ab.

13. food habit\$.ti,ab.

14. poor diet.ti,ab.

15. or/7-14

16. healthy eating.ti,ab.

17. (fruit or vegetable\$ or exercise\$).ti,ab.

18. exp Health Behavior/

19. health behavior.ti,ab.

20. health behaviour.ti,ab.

21. health behaviour.ti,ab.

22. (intervene $\$$ or intervention\$).ti,ab.

23. or/16-22

24. 6 and 15 and 23

25. limit 24 to (english language and $y r=" 1996-2007 ")$

\section{Embase 220906}

1. socioeconomic factor\$.ti,ab.

2. exp Socioeconomic Status/

3. socioeconomic status.ti,ab.

4. (disadvantage $\$$ or depriv $\$$ or poverty or low income).ti,ab.

5. (SES and status and low).ti,ab.

6. $\mathrm{or} / 1-5$

7. $\exp$ LIFESTYLE/

8. lifestyle $\$ . t i, a b$.

9. (activit\$ or inactivit\$).ti,ab.

10. ((weight and gain) or overweight).ti,ab.

11. exp OBESITY/

12. obesity.ti,ab.

13. food habit\$.ti,ab.

14. poor diet.ti,ab.

15. or/7-14

16. healthy eating.ti,ab.

17. (fruit or vegetable $\$$ or exercise $\$$ ).ti,ab.

18. exp Health Behavior/19. health behavior.ti,ab.

20. health behaviour.ti,ab.

21. health behaviour.ti,ab.

22. (intervene\$ or intervention\$).ti,ab.

23. or/16-22

24. 6 and 15 and 23

25. limit 24 to (english language and yr = "1996-2007")

\section{Medline (Ovid) 220906}

1. socioeconomic factor\$.ti,ab.

2. exp Socioeconomic Status/

3. socioeconomic status.ti,ab.

4. (disadvantage $\$$ or depriv\$ or poverty or low income).ti,ab.

5. (SES and status and low).ti,ab.

6. $\mathrm{or} / 1-5$

7. $\operatorname{exp~LIFESTYLE/~}$

8. lifestyle\$.ti,ab.

9. (activit\$ or inactivit\$).ti,ab.

10. ((weight and gain) or overweight).ti,ab.

11. exp OBESITY/

12. obesity.ti,ab.

13. food habit\$.ti,ab.

14. poor diet.ti,ab.

15. or/7-14

16. healthy eating.ti,ab.

17. (fruit or vegetable\$ or exercise\$).ti,ab.

18. exp Health Behavior/

19. health behavior.ti,ab.

20. health behaviour.ti,ab.

21. health behaviour.ti,ab.

22. (intervene $\$$ or intervention\$).ti,ab.

23. or $/ 16-22$

24. 6 and 15 and 23

25. limit 24 to (english language and yr ="1996-2007")

Psyclnfo (Ovid) 220906

1. socioeconomic factor\$.ti,ab.

2. exp Socioeconomic Status/

3. socioeconomic status.ti,ab. 
4. (disadvantage $\$$ or depriv\$ or poverty or low income).ti,ab.

5. (SES and status and low).ti,ab.

6. or $/ 1-5$

7. $\exp$ LIFESTYLE/

8. lifestyle $\$ . t i, a b$.

9. (activit\$ or inactivit\$).ti,ab.

10. ((weight and gain) or overweight).ti,ab.

11. exp OBESITY/

12. obesity.ti,ab.

13. food habit\$.ti,ab.

14. poor diet.ti,ab.

15. or/7-14

16. healthy eating.ti,ab.

17. (fruit or vegetable $\$$ or exercise $\$$ ).ti,ab.

18. exp Health Behavior/

19. health behavior.ti,ab.

20. health behaviour.ti,ab.

21. health behaviour.ti,ab.

22. (intervene\$ or intervention\$).ti,ab.

23. or $/ 16-22$

24. 6 and 15 and 23

25. limit 24 to (english language and yr = "1995-2007")

\section{Previously unobtained full-text papers $(n=21)$}

Full copies now obtained-all independently screened and excluded $(n=6)$

1. Croghan IT, O'Hara MR, Schroeder DR, et al. A community-wide smoking cessation program: quit and win 1998 in Olmsted County. Prev Med 2001;33:229-38.

2. Fernandez E, Schiaffino A, Borrell C, et al. Social class, education, and smoking cessation: long-term follow-up of patients treated at a smoking cessation unit. Nicotine Tob Res 2006;8:29-36.

3. Freels SA, Warnecke RB, Parsons JA, et al. Characteristics associated with exposure to and participation in a televised smoking cessation intervention program for women with high school or less education. Prev Med 1999;28:579-88.

4. Lazev AB, Vidrine DJ, Arduino RC, et al. Increasing access to smoking cessation treatment in a low-income, HIV-positive population: the feasibility of using cellular telephones. Nicotine Tob Res 2004;6:281-6.

5. Swinburn BA, Caterson I, Seidell JC, et al. Diet, nutrition and the prevention of excess weight gain and obesity. Public Health Nutr 2004;7:123-46.

6. Widga AC, Lewis NM, Fada RD. Defined, in-home, pre-natal nutrition intervention for low-income women. J Am Diet Assoc 1999;99:1058-62.

\section{Unable to obtain full-text copies $(n=9)$}

1. Cason KL, Scholl JF, et al. A comparison of program delivery methods for low income nutrition audiences. Topics Clin Nutr 2002;17:63-73.
2. Finkelstein EA, Troped PJ, et al. Cost-effectiveness of a cardiovascular disease risk reduction program aimed at financially vulnerable women: the Massachusetts WISEWOMAN Project. J Women's Health Gender-Based Med 2002;11:519-26.

3. Foley RM, and Pollard CM. Food Cent\$-implementing and evaluating a nutrition education project focusing on value for money. Aust NZ J Public Health 1998;22:494-501.

4. Freudenberg N, Silver D, et al. Health promotion in the city: a structured review of the literature on interventions to prevent heart disease, substance abuse, violence and HIV infection in US metropolitan areas, 1980-1995. J Urban Health 2000;77:443-57.

5. Kisioglu AN, Aslan B, et al. Improving control of high blood pressure among middle-aged Turkish women of low socio-economic status through public health training. Croatian Med J 2004;45:477-82.

6. Palmer TA, and Jaworski CA. Exercise prescription for underprivileged minorities. Curr Sports Med Rep 2004;3:344-8.

7. Shi L. Sociodemographic characteristics and individual health behaviors. Southern Med J 1998;91:933-41.

8. Walcott-McQuigg JA. Psychological factors influencing cardiovascular risk reduction behavior in low and middle income African-American women. $J$ Natl Black Nurses' Assoc 2000;11:27-35.

9. Will JC, Massoudi B, et al. Reducing risk for cardiovascular disease in uninsured women: combined results from two WISEWOMAN projects. J Am Med Womens Assoc 2001;56:161-5.

\section{Dissertations-excluded $(\mathrm{n}=\mathbf{6})$}

1. Davies SL. Using the transtheoretical model of change as a framework for understanding smoking behavior in a sample of low-income, hospitalized, African-American smokers. Dissertation Abstracts International: Section B: The Sciences and Engineering 1997;58(5-B).

2. De Vogli R. Socioeconomic determinants of healthy lifestyles: does psychosocial stress matter? Dissertation Abstracts International: Section B: The Sciences and Engineering 2004;65(2-B).

3. Dutton GR. Effects of a primary care weight management intervention on physical activity in low-income African American women. Dissertation Abstracts International: Section B: The Sciences and Engineering 2006;66(7-B).

4. Rounds TJ. Evaluation of a community-based home visiting program for low income families. Dissertation Abstracts International Section A: Humanities and Social Sciences 1997;57(8-A).

5. Roundtree WJ. An analysis of parental scaffolding among three AfricanAmerican mother-child dyads participating in the home instruction program for preschool youngsters (HIPPY). Dissertation Abstracts International Section A: Humanities and Social Sciences 2000;61(6-A).

6. Springer J. Health behavior change as it relates to the adoption of and adherence to a program of physical activity. Dissertation Abstracts International: Section B: The Sciences and Engineering 2005;65(7-B). 